\title{
Dental Emergencies during the COVID-19 No Aversion Therapy Centers
}

\author{
Findler $\mathrm{M}^{1}$, Bernstein $\mathrm{Y}^{1}$, Meidan $\mathrm{Z}^{1}$, Tobias $\mathrm{G}^{2 *}$, Manor $\mathrm{L}^{1}$ and Mann $\mathrm{J}^{1}$ \\ ${ }^{1}$ Dental Research Unit-Maccabi-Dent, Maccabi Healthcare Fund, Israel \\ ${ }^{2}$ Department of Community Dentistry, Hebrew University-Hadassah School of Dental Medicine, \\ Israel
}

*Corresponding author: Guy Tobias, Department of Community Dentistry, Hebrew University-Hadassah School of Dental Medicine, Jerusalem, Israel, Tel: 972527052333; Email: Guy.tobias@mail.huji.ac.il

\section{Research Article}

Volume 5 Issue 3

Received Date: July 13, 2020

Published Date: August 10, 2020

DOI: $10.23880 /$ oajds-16000265

\section{Abstract}

Introduction: Over six months have elapsed since the COVID-19 pandemic broke out in Wuhan China. The Israeli government along with the Ministry of Health begun, on March 11th, to enforce social distancing and other rules to limit the spread of the infection.

Materials and Methods: Patients in need of treatment were requested to call a phone center, provide information on the problem and provide medical information on themselves. The staff receiving the phone calls could check the dental files on line, and if the patients were not carriers of the COVID-19 they were referred to the clinic closest to their place of residence. The patients, for purpose of analysis, were divided into two groups: patients younger than 18, eligible for state financial coverage, and adults over 18.

Results: Maccabi-Dent had 650,000 individuals registered as patients at the beginning of the COVID-19 pandemic "era" and treated over 15,000 dental emergencies. no significant difference was found between recipients of care by age or gender. The total number of patients who received care in these clinics was $13,782,9,757$ adults $(71 \%)$ and $29 \%(4,025)$ children ages $0-17$. The total number of procedures was 20,409 of these $55 \%$ adults and $45 \%$ children.

Discussion: Patients avoided dental visits to locations which had a Corona virus treatment facility, yet, they came to dental clinics dedicated to dental emergencies only, with no proximity to a hospital.

Conclusion: It is recommended to locate the non-coronavirus emergency apart from epidemic and patient-associated centers combined with tele medicine centers.

Keywords: COVID 19; Public Health; Dental Treatment

\section{Introduction}

Over six months have elapsed since the COVID-19 pandemic broke out in Wuhan China. It started in China in December 2019 and spread to 213 countries and territories [1,2]. According to "worldometer" [1] the world, had, by July of 2020, well over $11,000,000$ confirmed Coronavirus Cases with over 6,500,000 recovered and over 4,500,000 currently infected patients with over 537,000 death cases. The first case in Israel was detected on February $21^{\text {st }} 2020$. Today in
Israel we have a total of over 332 deaths and over 12,000 active cases. The ratio in Israel is 2,100 cases per I million population and 35 deaths per I million population. The figures, at this point in time, as the second wave started to spread are not encouraging.

The Israeli government along with the Ministry of Health begun, on March 11th, to enforce social distancing and other rules to limit the spread of the infection [3-5]. On March 19th' the Israeli prime Minister declared a national state of 


\section{Open Access Journal of Dental Sciences}

emergency and various restrictions were enforced including closure of flights, limitations in leaving home, and many other restrictions which harmed the economy, as seen in many other countries around the globe [6]. In the US, in April, the unemployment rate rose to 14.7 percent and decreased recently to $13.3 \%$. The number of unemployed rose by 15.9 million to 23.1 million, the health care sector lost 1.4 million jobs. Half a million of these positions were in dental offices [7].

Lately, in Israel many of these restrictions were lifted, following other countries such as many of the European countries and the U.S. Under the assumption that we will not be hit by a second wave of Corona, many limitations will be lifted in the near future and "normal" life will be resumed with the ongoing rules of using masks, taking care of hygiene and keeping a minimal distance of 2 meters between people. Dentistry was part of the pandemia and most clinics in Israel were instructed to close down and only emergency dental treatments were allowed to be given, both in private practices and in HMO practices.

Maccabi-Dent is a large provider with 53 dental clinics around the country, with 400 dental chairs and over 1100 dentists out of approximately 6000 FTE dentists in Israel. Of this total number of providers only 84 were instructed to provide emergency treatment, in 27 clinics with a geographical spread trying to cover all the country. Emergency treatment was defined by the ministry of health, a definition which is similar to that in other westernized countries. The aim was to find the balance between public health elements; decreasing or preventing the spread of the Corona virus and the public's need for minimizing dental and oral pain during this period of time. Similar instructions were published by other leading institutions such as the NHS and the CDC $[7,8]$.

Now that we are gradually moving to a different routine and "normal" life, including opening the dental clinics while keeping track of the Corona virus and its spread continuation, we had the time to summarize this period of time with the aim of coming up with conclusions which might be of assistance if another wave will spread in the world.

This article is basically a descriptive one, presenting figures, yet aims at trying to find out if the solutions given to the patients were sufficient or should we, if a second strike will hit, change or improve, both in procedures and availability of services.

\section{Materials and Methods}

Medical care in Israel is provided, by law, to all citizens of the country. Medical care is provided by four medical health funds. The largest is Clalit Health Services which has almost 5 million members, Maccabi Healthcare services is the second largest with 2.3 million members. Each HMO provides dental care via a dental system which is independent, but receives funding also through the government which pays for some of the dental services via the HMO [9].

Maccabi-Dent, as mentioned above, has 53 clinics with 400 dental chairs and employs over 1100 dentists and 370 hygienists. On the 27th of February the first COVID-19 patient in Israel was diagnosed. The Ministry of Health acted immediately and dental services as part of the health regulation in all facilities across the country halted from providing elective dental treatment and only emergency treatment was allowed, starting March 19th [10].

Maccabi-Dent, accordingly, closed 26 clinics, while the other 27 served as centers for emergencies provided by 84 dentists. Patients in need of treatment were requested to call a phone center, provide information on the problem and provide medical information on themselves. The staff receiving the phone calls could check the dental files on line, and if the patients were not carriers of the COVID-19 they were referred to the clinic closest to their place of residence. Each patient, was given a time slot in which to receive the treatment in a dental clinic. On his arrival, surgical face mask was mandatory, body temperature was measured, in addition to a health questionnaire and some other information, so as to have a double check as to the patient not being a carrier. Disinfection of all surfaces within the dental clinic were performed between each patient, the care givers wore masks, gloves, gowns and goggles or face shields. A patient who was suspected of being a carrier was not treated and was sent to be tested for Corona virus.

Each patient who received emergency treatment was asked to return for further treatment, when the clinics reopen. Some of the patients returned for a second emergency treatment if the problem was not solved, yet, very few returned for a third visit. All cases were thoroughly documented. This service was provided between March $19^{\text {th }} 2020$ to April $30^{\text {th }}$. The day the elective services were permitted. Needless to say that also these were under the regulations of the Ministry of Health. Complete medical records from patient's files between these dates were found in the information system of the Macabi-Dent Clinic Network. The patients for purpose of analysis were divided into two groups: patients younger than 18, eligible for state financial coverage, and adults over 18. Those between the ages of 18-21 are usually in military service and hence only a relative small number of this age group is presented in this study. Data on treatments provided, according to the major dental complaint, was collected. 


\section{Results}

Maccabi-Dent had 650,000 individuals registered as patients at the beginning of the COVID-19 pandemia "era". In order to provide emergency services, as a basic obligation to all patients, 27 clinics were prepared so as to take care of those in need. According to Figure 1 the total number of patients who received care in these clinics was 13,782 , of these 9,757 adults (71\%) and 29\% (4,025) children ages $0-17$. The total number of procedures was 20,409 of these $55 \%$ to adults and $45 \%$ to children.

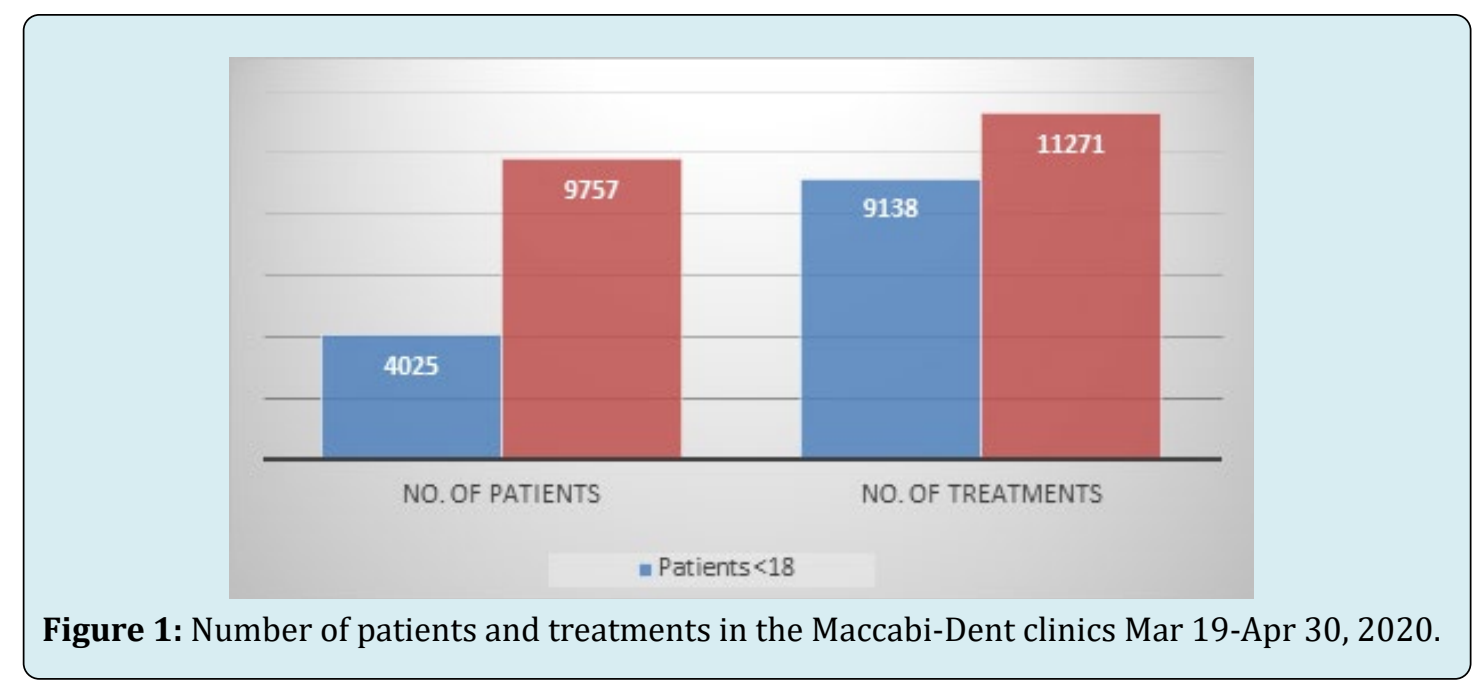

Mean number of treatments provided to children under age 18 was 2.27 and for adults was 1.16 . A look at the total population indicates 1.48 treatments per patient. Average age for patients under the age of 18 was 11.5 years and among patients above 18 years old, the mean age was 43.35 .

Figure 2 shows the number of patients who received dental emergency care in each age group from March 19th 2020 to April 30th 2020, the coronavirus period, with the peak amongst those at the age of 50 . As the age increased the number of patients receiving care decreased. In order to further analyze this finding, we looked at the number and age of patients who received routine treatment during March $1^{\text {st }}$ and April $30^{\text {th }}$ of 2019 as compared to the same months in 2020, the two graphs seemed alike (Figures $3 \& 4$ ). Similar to the results for the COVID-19 period (March 19 ${ }^{\text {th }}-$ April 30 ${ }^{\text {th }}$ ). Graphs 2-4 shows the same trend of decrease of patients in age groups older than 50 years. We further investigated the demand for treatment for March $1^{\text {st }}$ to April 30 2020 and March $19^{\text {th }} 2020$ to April $30^{\text {th }} 2020$ as a percent of March $1^{\text {st }}$ to April 30 2019 period. The demand for emergency care during the Coronavirus period had the same trend as the March-April one, yet, with a much lower phase to about 8.5\%. This indicates that the demand for treatment among different age groups was similar in all three graphs presented, yet, the need for dental care changed from phase to phase.

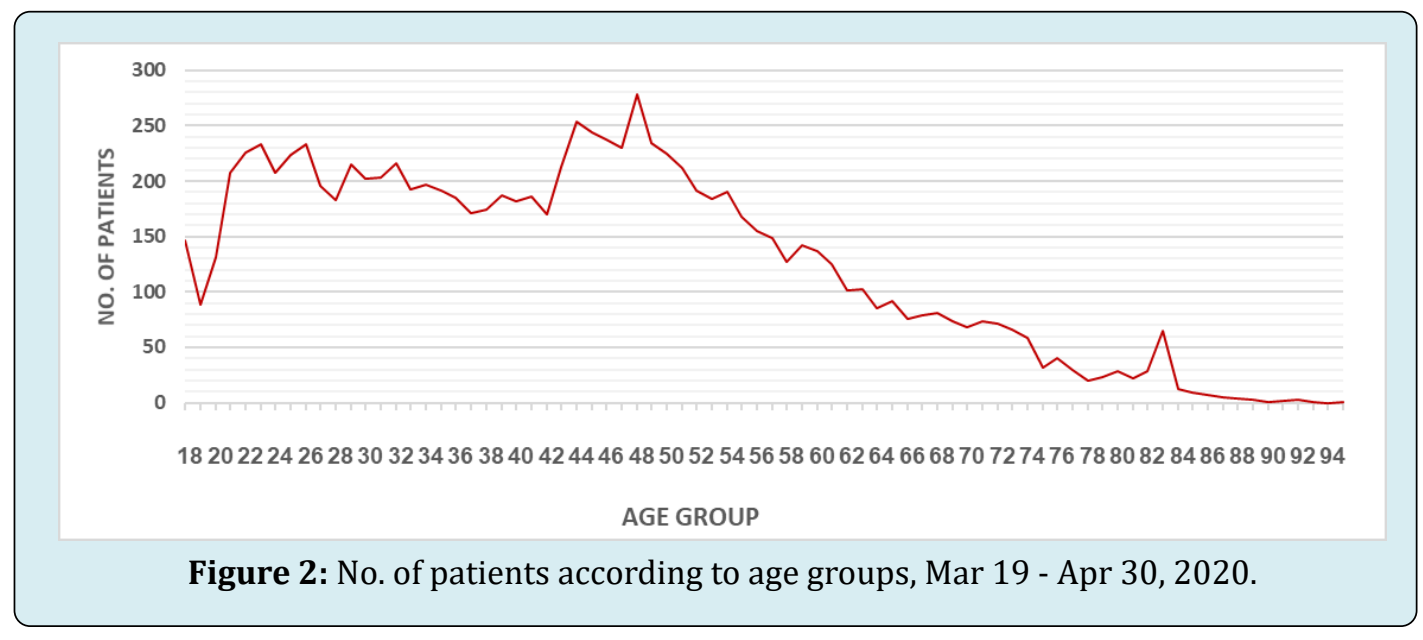




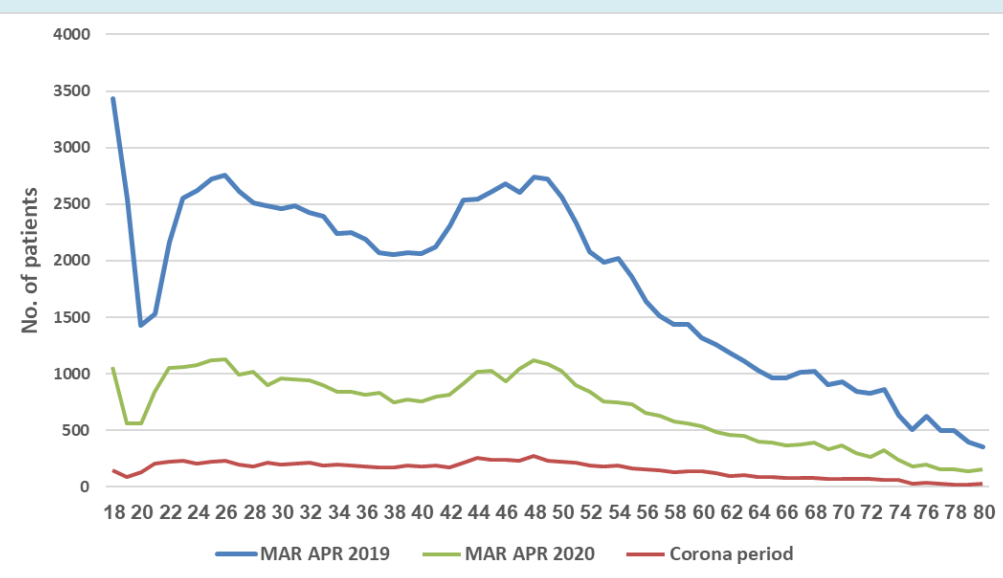

Figure 3: No. of patients according to age groups in 3 various periods of time.

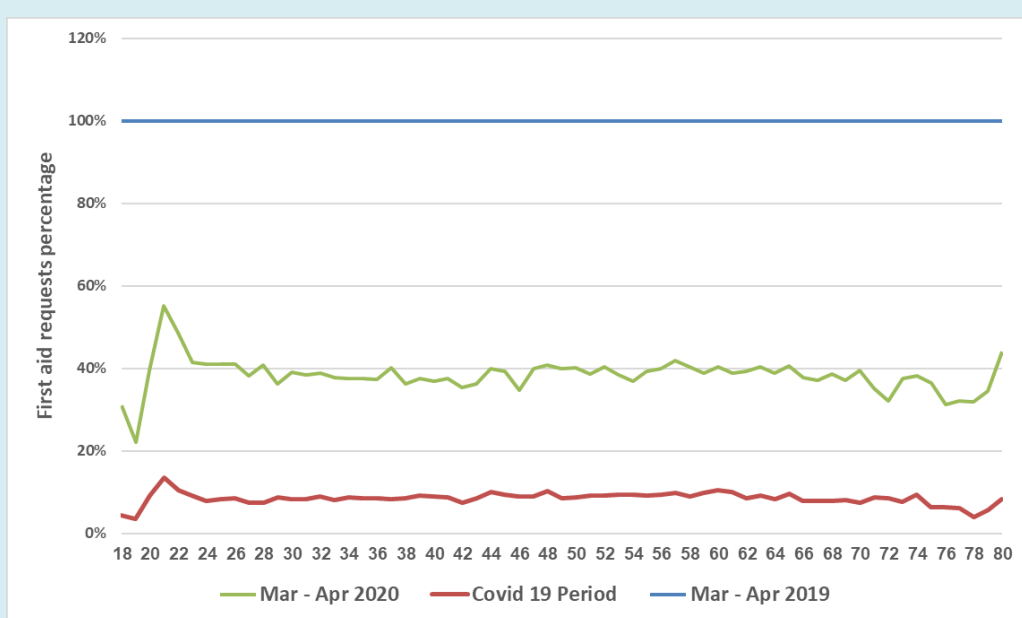

Figure 4: Percentage of emergency treatments compared to the corresponding period of 2019 by age group.

Figure 5 presents the reasons for the need of emergency treatment. The distribution was as follows: 7048 examinations followed by proper instructions with or without medication prescription, 2462 chewing disorders, 477 infection, 1161 pain, only 123 were classified as nonemergency cases, and some had no reason documented.

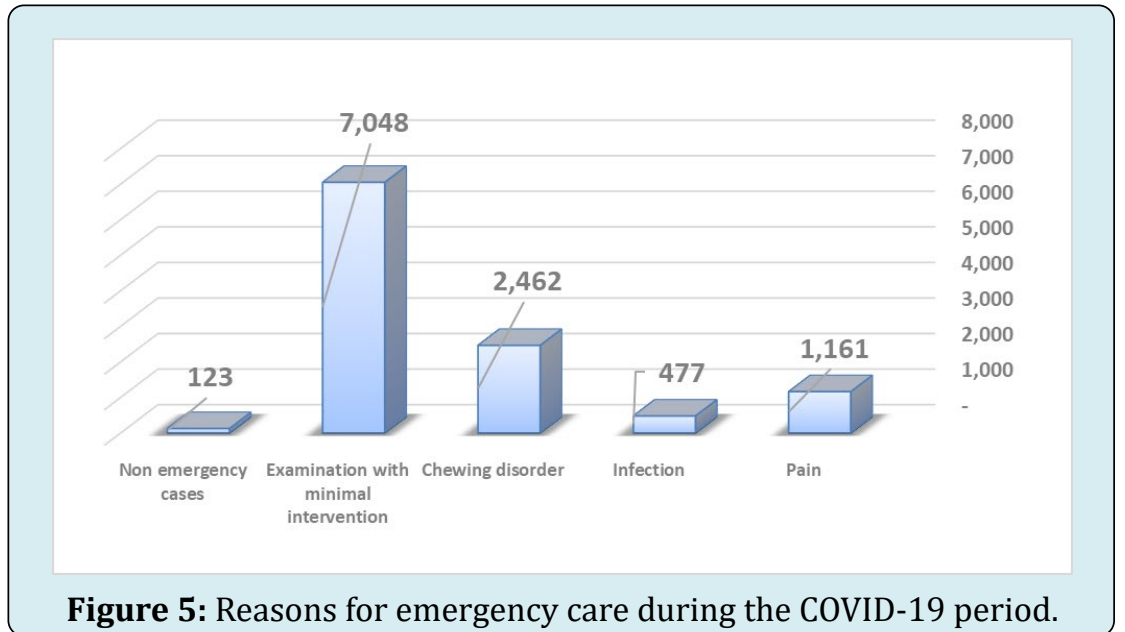




\section{Open Access Journal of Dental Sciences}

\section{Discussion}

The Covid-19 virus is continuing to spread around the world, now in the US, Brazil, Peru, Mexico, Russia, Egypt and other countries around the globe. It seems as if in some countries, the first wave is behind them, yet, a second wave is on the way. In Israel, the number of new cases dropped to near zero, but it has increased again in the last few days, especially in schools threatening to shut down various activities again [1]. Those countries which have suffered and are still suffering are trying to find ways to cope, if and when, the second strike will hit. This article, not only brings a wide range of information from a large care giver in Israel, but also aims at coming up with conclusions and thoughts for the future. A paper published recently in the NEJM by Wong, et al. [11] concluded that "there is increasing evidence that patients with medical emergencies are avoiding the emergency departments because of fear of contracting Covid-19, leading to increased morbidity and mortality".

Is this behavior also compatible with dentistry, knowing that the focus of the infection is in the oral cavity? An article published in 2020 by Sommer, et al. [10] reported that the effect of Covid-19 pandemic on oral medicine services in a tertiary referral center which was located in a hospital in Israel which became a primary center for treatment of Infected Covid-19 patients that the oral medicine unit treated, during the period of March 17th to the end of April, 194 patients of which $77.3 \%$ of the visits were related to dental emergencies and $22.5 \%$ were urgent oral cavity diseases. There was a dramatic reduction in patient attendance to dental care as well as to periodontal maintenance. Saying so, the decrease in the number of patients was also a result of the quarantine. In 2019 in between March 1st and April 30th we received 1895 patients a day, in between the same dates in 2020 we treated 729 patients a day, during the closure we treated 162 patients a day, mostly emergency cases, this is a figure representing $8.5 \%$ of the regular bulk of patients. In the UK the figure was found to be 6-9\%, there was no reduction in the demand of older patients who are at higher risk to be affected by the Covid-19 [12].

It seems as if [11,13], in the era of the Covid-19 pandemic, some patients' perception of the hospital had changed from a place of safety and shelter to one of danger and fear and hence avoided treatment which could be provided in other dental facilities, a place in which the risk of acquiring Covid-19 is limited. The Maccabi-dent clinics are independent, treat only dental patients and are not adjacent to hospitals, so the risk of acquiring the disease is limited.

Covid-19 patients do present a challenge for healthcare professionals and the whole medical system [13]. Due to the characteristic of dental settings, the risk of cross infection can be high between patients and dental practitioners [2]. Treatment of dental patients who have been exposed to the Covid-19 virus or those who are at risk, is complicated and expensive. In addition, patients do prefer, in an emergency, to receive treatment in a facility in which the chances to be infected by the virus are slim. Dental clinics and perhaps emergency medical centers should be remote from the reception and treatment centers for pulmonary symptomatic patients and coronavirus disease patients.

Patients from all age groups received dental treatment at the dental facility with all precautions taken. To the best of our knowledge no cases of Corona virus were reported among our dentists or among other members of the dental team. The most important conclusion of this article is that in the future if another wave of the Covid-19 is on the way or if in the future some other virus epidemic will erupt, it is crucial to do our best and prepare for such an episode by having dental clinics and manpower with no physical connection with hospitals, in addition, as we have begun to develop, a telemedicine service should be available so to be able to direct patients to the clinic which is the one closest to their geographical residence and provide the best information so as to assist the one in need or understand that the patient, according to the information provided, might not need immediate intervention.

\section{Conclusion}

Dental emergency care was one of those services provided in most western countries. In Israel the service was allowed following the instructions sent out by the Ministry of Health. Treatment was provided by private practices, by hospitals which had dental facilities and mainly by sick funds. Maccabi- dent which is a very large provider, treated over 15,000 dental emergencies, both of children and of adults. This study demonstrated a very interesting phenomenon. Patients avoided dental visits to locations which had a Corona virus treatment facility, mainly hospitals, yet, in dental clinics dedicated to dental emergencies only, with no proximity to a hospital, the number of patients, decreased, in comparison to regular times, but no significant difference was found between recipients of care by age or gender. It is strongly recommended to strengthen this avenue of care in the future bonded with strong tele-dentistry.

\section{References}

1. WORLDOMETER-real time world statistics.

2. Meng L, Hua F, Bian Z (2020) Coronavirus Disease 2019 (COVID-19): Emerging and Future Challenges for Dental and Oral Medicine. J Dent Res 99(5): 481-487. 
3. Gehani CP (2020) Recovery is a multifaceted effort. ADA.

4. https://www.health.gov.il/hozer/DT01_03.pdf

5. https://www.health.gov.il/hozer/dent_2020155728020.pdf

6. (2020) Employment Situation Summary. U.S. Bureau of Labor Statistics.

7. CDC Recommendation: Postpone Non-Urgent Dental Procedures, Surgeries and Visits.

8. https://www.england.nhs.uk/coronavavirus/ wp-content/uploads/sites/52/2020/03/issue-3preparedness-letter-for-primary-dental-care-25march-2020.pdf

9. Wikipedia- healthcare in Israel. Healthcare in Israel.
10. Sommer MU, Davidovitch T, Platner O, Inerman A, Yarom $N$ (2020) The effect of Covid-19 pandemic on oral medicine services in a tertiary referral Israel Ministry of Health.

11. Wong ES, Hawkins JE, Langness S, Murrell KL, Iris P, et al. (2020) Where Are All the Patients? Addressing Covid-19 Fear to Encourage Sick Patients to Seek Emergency Care. NEJM.

12. White DA, Tsakos G, Pitts NB, Fuller E, Douglas GVA, et al. (2012) Adult Dental Health Survey 2009: common oral health conditions and their impact on the population. BDJ 213(11): 567-572.

13. Itelman E, Wasserstrum Y, Segev A, Avaky C, Negru L, et al. (2020) Clinical characterization of 162 COVID-19 patients in Israel: Preliminary Report from a Large Tertiary Center. 22(5): 271-274. 